DOI: https://doi.org/10.47405/mjssh.v6i11.1163

\begin{tabular}{|c|c|}
\hline 4 & Malaysian Journal of Social Sciences and Humanities (MJSSH) \\
\hline $\begin{array}{l}\text { Malaysian Juoural of } \\
\text { Social ccciecces and }\end{array}$ & Volume 6, Issue 11, November 2021 \\
\hline (MJ-sSH) & e-ISSN : 2504-8562 \\
\hline & $\begin{array}{l}\text { Journal home page: } \\
\text { www.msocialsciences.com }\end{array}$ \\
\hline
\end{tabular}

\title{
Consumer Acceptance of Fermented Drinks in Malaysia
}

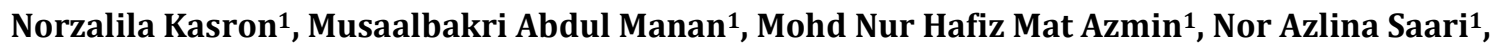 \\ Malisah Abd Latip ${ }^{2}$ \\ 1Malaysian Agricultural Research and Development Institute (MARDI), Persiaran MARDI-UPM, 43400 Serdang, \\ Selangor, Malaysia. \\ ${ }^{2}$ Faculty of Humanities, Management and Science, University Putra Malaysia Bintulu Campus, Sarawak, Malaysia.
}

\author{
Correspondence: Norzalila Kasron (norzalila@mardi.gov.my)
}

\begin{abstract}
Fermented beverages have become a powerful player in the global beverage sector because of the increased demand for health products and their nutritional benefits to societies. This study aimed to identify consumer acceptance and willingness to pay for fermented drinks developed by MARDI. It also will evaluate the market potential of products among industry players. In this study, the data was collected using structured questionnaire and face-to-face interviews focused on the population in Peninsular Malaysia. The population's selection by stratified random sampling technique and the major survey locations included mall and hypermarket. Exploratory factor analysis (EFA) was used to discover the underlying structure of observed variables. A total of 400 respondents had participated in the study. A field survey conducted showed that $54 \%$ of respondents knew about functional foods and $55 \%$ of these are aware of functional foods based on fruits were in the market. The survey found that $30 \%$ of respondents had taken fermented drinks before, while the rest had never known this drink. Age and income have a significant influence on consumers' willingness to pay fermented drinks at a reasonable price if this product is available in the Malaysian market. Government support is needed to encourage the cultivation of indigenous fruit in Malaysia. It can be done through the provision of seed subsidies and financial resources to farmers in expanding and increasing the supply of these raw materials for the production of value-added products.
\end{abstract}

Keywords: consumer acceptance, exploratory factor analysis (EFA), fermented drinks, indigenous fruits, willingness to pay

\section{Introduction}

Food and beverage industry accounts among the most developed sectors, being constantly changing. Even though a basic beverage industry could be found in every area of the globe, particular aspects in beverage production, processing, and consumption are identified in some geographic zones (Liburdi et al., 2020; Watawana et al., 2015). An impressive progress has recently been observed in both traditional and modern beverage industries and these advances are leading beverages to a new era. Along with the cutting-edge technologies, developed to bring innovation and improve beverage industry, some other human-related changes also have a great impact on the development of such products. On top of that, the global functional beverage market is a growing sector of the food industry as modern health-conscious consumers show an increasing desire for foods that can improve wellbeing and reduce the risk of disease (Sahu \& Panda 2018). Fermented products have undergone a surge 
in popularity as a functional food choice, mainly due to their nutritional properties and proposes health benefits (Dimidi et al., 2019). Studies have shown that consumption of fermented foods may improve intestinal and extraintestinal health and might be useful in improving and treating infectious diarrhea, reducing the duration and incidence of respiratory infections, enhancing immune and antiinflammatory responses (Kok \& Hutkins, 2018). At present, functional fermented beverages could be the most popular due to their convenience and possibility to meet consumer demands of handling for container contents, size, shape, appearance, as well as ease of distribution, storage, and opportunity to incorporate desirable nutrients and bioactive compounds (Corbo et al., 2014).

Fermented beverages hold a long tradition and have become an influential player in the global beverage economy, because of the growing demand for health products and contribution to the nutrition of many societies worldwide (Liburdi et al., 2020). The global market size of the fermented beverage, as example made using consortium of fermented drinks strain, or symbiotic culture of yeasts and acetic acid bacteria, is anticipated to hit 6.2 billion USD by 2026, according to a report by Acumen Research and Consulting, a provider of market research studies. It estimates the market is anticipated to grow with 23 per cent CAGR during the forecast time period. Generally, nutritional attributes of food can be improved by fermentation, which may provide better organoleptic properties (such as, taste, aroma, and texture) metabolism, digestion, and absorption and favourable constituent of fermented food. Because of their great beneficial effects, fermented products still represent an important industrial and research domain (https://www.acumenresearchandconsulting.com/kombucha-market). In addition to harnessing traditional beverages for commercial use, there have recently been innovative efforts to develop non-dairy probiotic fermented beverages from a variety of substrates, including fruit juices.

Ceri Terengganu (Lepisanthes fruticosa) and Kuini (Mangifera odorata) juices could serve as suitable media for cultivating consortium of fermented drinks strain for fermented beverages production. The Ceri Terengganu and Kuini juices supplemented with sugar allowed to ferment under aerobic conditions. The consortium of fermented drinks strains involves yeasts and acetic acid producing bacteria live together symbiotically to convert the sugared Ceri Terengganu and Kuini juices to form new fermented products through fermentation. The fermentation affected physiochemical and sensory properties of the juices. With a focus on the promising new value-added healthy products, the fermentation enhanced the antioxidant and antimicrobial activities of the resulting product, so also were the bioactive compounds, with the desirable overall properties of the fermented beverages. As the fermentation progresses, the taste of fermented Ceri Terengganu and fermented Kuini juices changes from a pleasurably fruity, sour and tartness taste, thus increasing the consumer acceptability of the flavor and other sensory aspects of the beverage. Ultimately, a pleasantly sweet and sour, slightly pungent (because high in organic acids), apple cider-like beverage is produced. The low $\mathrm{pH}$ of the beverage is attributed to the production of various organic acids during fermentation. The antioxidant activity demonstrated is thought to be due to the various biophenolic and bioflavanoid compounds. In vivo studies showed that both fermented products had non-toxicity effect. A glimpse of study carried out in MARDI revealed that the fermented Ceri Terengganu and fermented Kuini beverage is a good source of the bioactive compounds which make it as a functional beverage.

The objectives of the study are to identify consumer acceptance and willingness to pay of fermented drinks developed by MARDI. It also will evaluate the market potential of products among industry players.

\section{Methodology}

The study involved 400 respondents in data collection using a structured questionnaire and face-to-face interviews focused on the population in Peninsular Malaysia. The population's selection by stratified random sampling technique ensures the population's subgroup represented $\mathrm{N}$ population, and four zones are chosen, which are north $(n=100)$, south $(n=100)$, west $(n=100)$ and east $(n=100)$, and the major survey locations included mall and hypermarket. 
Food testing is conducted four samples which are three fermented drinks produce by MARDI and product in the market that has characteristics (taste, color) equivalent to MARDI's. Consumers are required to taste the samples provided to evaluate the colour, sweetness, acidity, flavour, aroma, viscosity and after taste. Respondents answered the question by marking the preferred answer based on the Likert Scale which is $1=$ Strongly Dislike, $2=$ Dislike, $3=$ Neutral, $4=$ Like and $5=$ Very Like.

Exploratory factor analysis (EFA) was used to discover the underlying structure of observed variables (Mvududu et al., 2013). It was a data reduction technique used to reduce many variables to a small set of underlying factors that summarize the essential information contained in the variables (Richard et al. 2007). A Kaiser-Meyer-Olkin (KMO) test and Bartlett's Test of Sphericity were conducted to verify if the data set was suitable for factor analysis. The purpose of both tests is to measure the sampling adequacy to determine the factorability of the matrix or data set as a whole (Richard et al., 2007). If Bartlett's Test of Sphericity is large and significant, and the KMO measure is greater than 0.50, assumed that the data set's factorability exists. Factor loading is the correlation coefficient for the variable and factor. Factor loading shows the variance explained by the variable on that particular factor, and the value must exceed 0.3 . The value of eigenvalues must exceed ' 1 ' in order to classify it as one factor. Each item's communality value must be within the 0.3 range to confirm whether all factors extracted from this analysis are reliable or not, as suggested by MacCallum et al. (1999).

The respondent's WTP is represented by the dichotomous variable of WTP, with values of 1 for those willing to pay the additional amount and 0 is otherwise. Then the logistic regression technique is used to estimate the WTP (Hanemann, 1984). This method can estimate the probability of answering YES for the independent variable rate bid and some assumptions are made regarding the upper limit values and lower limits for the integral for each bid rate, the probability of saying 'YES' is one (1) while the probability of saying 'NO' is zero (0). As a result, the negative value of WTP can be deducted and zero is used as a lower limit value. Several studies on willingness to pay for healthy food products have been conducted across the globe (Krystallis, 2005). The regression model to determine the real value of the willingness to pay is as follows:

$\mathrm{WTP}=\left[\mathrm{B}_{0}+\left(\mathrm{B}_{2} \mathrm{X}_{2}+\mathrm{B}_{3} \mathrm{X}_{3}+\ldots, \mathrm{B}_{\mathrm{K}} \mathrm{X}_{\mathrm{K}}\right)\right] / \mathrm{B}_{1}$

Where:

$\mathrm{B}_{0} \quad=$ Coefficient value for constant

$\mathrm{B}_{2} \mathrm{X}_{2}=$ Coefficient value for $\mathrm{X}_{2}$

$\mathrm{B}_{3} \mathrm{X}_{3} \quad=$ Coefficient value for $\mathrm{X}_{3}$

$\mathrm{B}_{\mathrm{K}} \mathrm{X}_{\mathrm{K}} \quad=$ Coefficient value for $\mathrm{X}_{\mathrm{K}}$

$\mathrm{B}_{1} \quad=$ Nilai koefisien bagi $\mathrm{X}_{1}$

Market pre-validation is an evaluation activity in industry to gather feedback and to improve the product based on suitability and industry needs to ensure the products were ready for commercial phase (Semick, 2021). The process was used to minimize risk for product failure in commercialization phase. The failure happened when gut feeling was used in research area. It was a situation where the technologies developed based on technology push and not by demand pull. According to Andreessen (2021), product market fit was needed to ensure the products meet consumer's demand. The ProductMarket Fit Pyramid applied which contents 6 steps hierarchical for completing the process of productmarket validation and achieving product-market fit. developed by Dan Olsen, The Lean Product Playbook (Figure 1).

There are two layers of Product Market Fit Pyramid which are Market and Product. Market elements were target consumers and undeserved needs. Target consumers are important to predict potential consumers by applying the products attributes in real situation. While undeserved needs are products improvement that address consumers need in terms of attributes and the benefits. Products elements were including value proposition, feature set and user experience. The good and quality products were important to ensure it long lasting in market and gain more profit. It is hard for new products to penetrate and compete with the other established brand that available the market. Value proposition explain the value of that can be differentiate with competitive products. It should be explained the 
uniqueness and speak to the pain points of the target consumers. Feature set is an understanding of functionality of the products and create the value to validate that product are heading in the right direction. User experience is used to validate and test the value proposition and feature set that created with targeted consumers. It was product measurement to ensure the product were accepted in the market. The products will be testing in the market base on the validity of the product. Interview, focus group discussion and survey were part of the products testing to measure consumers preference, and perception.

Figure 1: Product Market Fit Pyramid

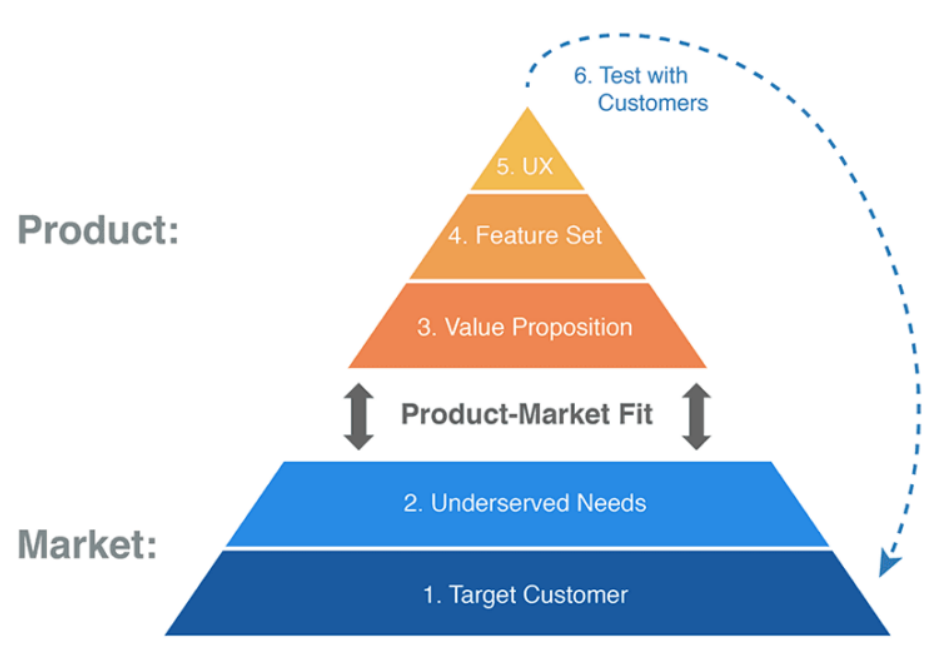

Source: The Lean Product Playbook

\section{Result}

\section{Consumers Acceptance}

Significant findings determine factors that influence the purchasing of fermented drinks and the willingness to pay (WTP) of the consumer on this product. The study found that $68 \%$ of the respondents involved in this study were above 40 years old. 59\% of respondents have higher education in IPT (Institute of Higher Learning), while the rest have education at the secondary school level and below. Respondents working in the private sector are 35\%, 32\% work in the government sector, $12 \%$ are self-employed, and the rest are retirees, housewives and students. According to Malaysia's definition, three income range group classified, namely B40, M40 and T20. Income less than RM4,850 was under the B40 group (72\%) less than RM10,970 was under M40 (22\%). The rest are respondents from the T20 group, with an income range exceeding RM10,971.

Table 1: Demographic profile of consumer survey $(n=400)$

\begin{tabular}{lll}
\hline Item & Characteristic & \% \\
\hline Age & $<=20$ & 7 \\
& $21-30$ & 30 \\
& $31-40$ & 31 \\
& $41-50$ & 22 \\
& $51-60$ & 7 \\
Education Level & $>60$ & 3 \\
& Primary school & 2 \\
& Secondary school & 38 \\
Job & Higher education & 59 \\
& No formal education & 1 \\
\hline
\end{tabular}




\begin{tabular}{|c|c|c|}
\hline \multirow{11}{*}{ Household Income } & Private & 35 \\
\hline & Self-employed & 12 \\
\hline & Retiree & 4 \\
\hline & Housewife & 6 \\
\hline & Student & 11 \\
\hline & $<\mathrm{RM} 2,500$ & 41 \\
\hline & RM2,501 - RM4,850 & 31 \\
\hline & $\mathrm{RM} 4,851$ - RM7,100 & 13 \\
\hline & RM7,101 - RM10,970 & 9 \\
\hline & RM10,971 - 15,040 & 5 \\
\hline & $>$ RM15,041 & 1 \\
\hline
\end{tabular}

Malaysians tends to consume less processed food products than consumers of developed countries (Stanton et al. 2011). However, at the same time reluctant to change the eating habits even though realized that are unhealthy food was taken (Williamson et al., 2000). A field survey conducted showed that $54 \%$ of respondents knew about functional foods and $55 \%$ of these are aware of functional foods based on fruits were in the market (Figure 1). However, there are only $41 \%$ of respondents that practice the intake of functional food based on fruits in daily life. The study proves that is still needs to be expanded to educate more consumers about the nutrients found in consuming functional food products.

Figure 1: Consumer Awareness and Consumption of Functional Food

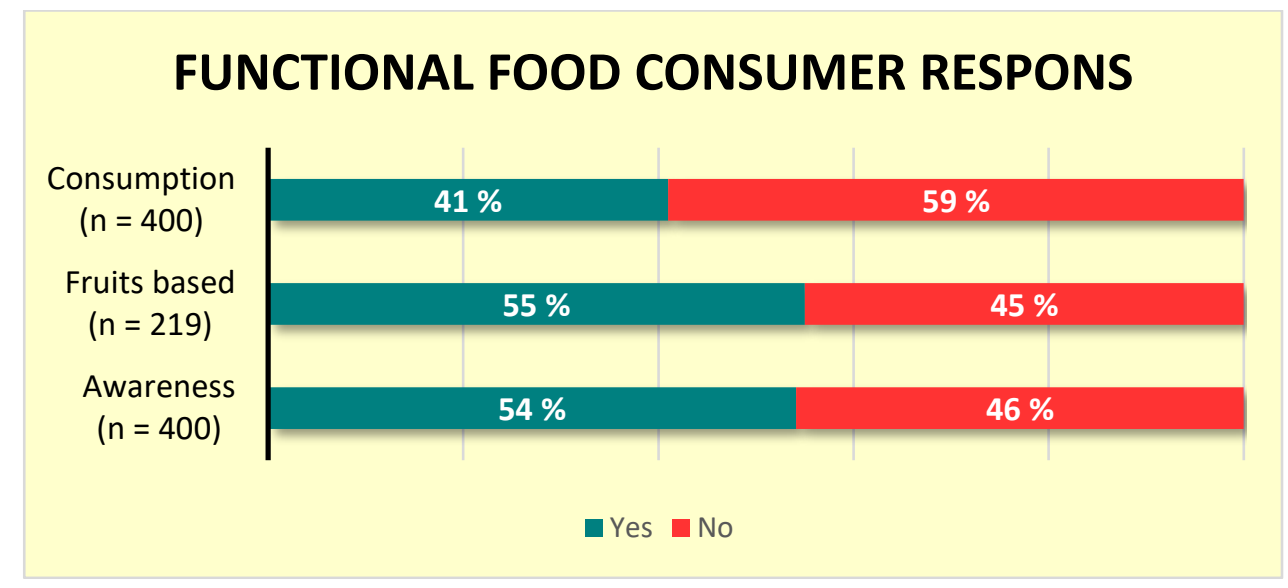

Consumption of fermented foods and drinks increases to $149 \%$ in 2018 . The result shows developments in fermented drinks consumption, a popular fermented beverage for health-conscious people (Saxe, 2019).

Figure 2: Consumer Consumption of Fermented Drinks

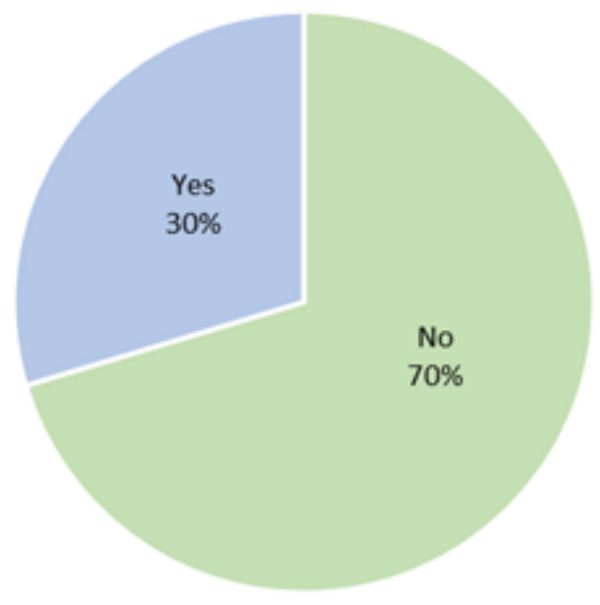


Although fermented drinks in Malaysia is considered new compared to other countries such as Australia and the United States, it still has its fans as the drink was produced traditionally before entering the market commercially. The survey found that $30 \%$ of respondents had taken fermented drinks before, while the rest had never known this drink.

A taste survey conducted on three products produced by MARDI (fermented drinks tea, Ceri Terengganu and kuini) and fermented drinks available in the market found that consumers prefer tea flavours in terms of colour, sourness, viscosity and after taste. In contrast, the sweetness and fruits taste more to the ceri Terengganu's flavour. The aroma of fermented drinks available in the market is excellent compared to three MARDI products which give a strong and less pleasant aroma (Table 2).

Table 2: Statistical Descriptive Analysis of Fermented Drinks Products.

\begin{tabular}{|c|c|c|c|c|c|c|c|c|}
\hline \multirow[b]{2}{*}{ Characteristics } & \multicolumn{2}{|l|}{ Tea } & \multicolumn{2}{|l|}{ Kuini } & \multicolumn{2}{|c|}{ Ceri Terengganu } & \multicolumn{2}{|c|}{ Existing Product } \\
\hline & Mean & $\begin{array}{l}\text { Std. } \\
\text { Deviation }\end{array}$ & Mean & $\begin{array}{l}\text { Std. } \\
\text { Deviation }\end{array}$ & Mean & $\begin{array}{l}\text { Std. } \\
\text { Deviation }\end{array}$ & Mean & $\begin{array}{l}\text { Std. } \\
\text { Deviation }\end{array}$ \\
\hline$\overline{\text { Colour }}$ & 3.60 & 1.024 & 3.25 & 1.157 & 3.58 & 1.142 & 3.41 & 1.152 \\
\hline Sweetness & 3.08 & 1.146 & 3.03 & 1.198 & 3.09 & 1.192 & 3.07 & 1.160 \\
\hline Sourness & 3.20 & 1.366 & 3.12 & 1.356 & 3.09 & 1.315 & 3.04 & 1.217 \\
\hline Fruit Taste & 3.16 & 1.133 & 3.11 & 1.148 & 3.21 & 1.179 & 3.01 & 1.128 \\
\hline Aroma & 2.93 & 1.207 & 2.93 & 1.168 & 2.82 & 1.217 & 3.01 & 1.197 \\
\hline Viscosity & 3.30 & 1.153 & 3.22 & 1.151 & 3.21 & 1.152 & 3.20 & 1.163 \\
\hline After Taste & 3.16 & 1.240 & 3.11 & 1.252 & 3.07 & 1.281 & 3.10 & 1.206 \\
\hline
\end{tabular}

Out of the 14 variables analyzed, the KMO gave a value of 0.907 , while the Barlett's test was significant at $0.01(\mathrm{p}$-value $=0.000)$. The result shows that factor analysis can identify the main factors that influence fermented drinks purchase. Eigenvalues exceeding 1.0 are considered factors that influence the purchase. The analysis reduced the number of items to 13 extracted into two factors that both described 53.5\% variance in the study. This factor is categorized as Product and Marketing, and Promotion. The first factor, labelled Product and Marketing, explains $43.68 \%$ of the total share. Nine variables represent this factor, and four of them give a high correlation value (>0.7), namely marketing method (0.706), peak advertising hour (0.710), advertising channel (0.743) and nutritional value (0.753). This marketing method refers to online or conventional marketing, such as through supermarkets or stores. This study found that $62.2 \%$ of respondents agree if the sale is online since it was easily accessible. While $67 \%$ of respondents agree if the advertising channel is done through social media, as at this time, social media plays a significant role in marketing a product. $47 \%$ of respondents think fermented drinks sale in glass bottles is more since this product is a volatile beverage. The second factor is Promotion which explains $9.80 \%$ of the total share. Four variables represent this factor, and 3 of them give a high correlation value of more than 0.7 . The variables that have a high correlation value are the price offered $(0.754)$, the product brand $(0.758)$ and the discount $(0.761)$.

Table 3: Factor Influencing the Purchase of Fermented Drinks

\begin{tabular}{lll}
\hline Item & Factors & \\
& Products and & Promotion \\
\hline Price & & 0.754 \\
Discount & & 0.761 \\
Brand & & 0.758 \\
Bottle size (30ml, 300ml) & 0.511 \\
Labelling & 0.640 & \\
Type of Packaging (Plastic bottle, glass bottle, & 0.635 & \\
sachet, box ) & & \\
Nutrition & 0.759 & \\
Producer (Local, imported) & 0.551 & \\
Advertising channel (social media, electronics, & 0.743 &
\end{tabular}




\begin{tabular}{lll} 
Advertising in peak hours & 0.710 & \\
Eye level & 0.679 & \\
Easy to access & 0.641 & \\
Method of marketing (Online, conventional) & 0.706 & 1.274 \\
\hline Eigenvalue & 5.678 & 9.797 \\
Variance (\%) & 43.676 & 53.473 \\
Cumulative (\%) & 43.676 & \\
\hline KMO & 0.907 & \\
Bartlett's Test of Sphericity & 0.000 & \\
\hline
\end{tabular}

Based on the estimation results, equivalent WTP measures were determined using logistic regression at the coefficient value (Table 4). Logistic registries assign a residual variable WTP with a value of either 1 or 0 for 'Yes' or 'No' responses. The independent cohort consists of bid prices and other factors, including gender, age, income and education. Income is significant with a coefficient of 0.741 , indicating that the higher the respondents' income, the higher the willingness to pay respondents for fermented drinks products. Age and income have a significant influence on consumers' willingness to pay fermented drinks at a reasonable price if this product is available in the Malaysian market. The regression analysis indicated a significant negative relationship at 5\% between age and WTP for fermented drinks price (bid value) with coefficient value -0.618 consumers' willingness which young people tend to pay higher value to consume fermented drinks instead of older people. The actual price bid is RM2.40 / bottle (30ml); however, after analysing using the WTP formula, the price willing to be paid by respondents is RM1.90/ bottle $(30 \mathrm{ml})$. This finding is consistent with economic theory, which shows that demand will decline when prices rise. It can see that the WTP decline as the prices asked of respondents' increase, by economic theory (Hanley et al., 2009). This also means the higher the bid value offered, the higher the response to not paying for fermented drinks.

Table 4: Consumers' Willingness to Pay, $\mathrm{N}=400$

\begin{tabular}{|c|c|c|c|c|c|c|}
\hline Item & B & S.E. & Wald & df & Sig. & $\operatorname{Exp}(B)$ \\
\hline Bid Price & -0.202 & 0.084 & 5.776 & 1 & 0.016 & 0.817 \\
\hline Gender & -0.464 & 0.241 & 3.717 & 1 & 0.054 & 0.629 \\
\hline Age & $-0.618 * *$ & 0.270 & 5.241 & 1 & 0.022 & 0.539 \\
\hline Income & $0.741 * * *$ & 0.267 & 7.706 & 1 & 0.006 & 2.097 \\
\hline Education & 0.265 & 0.250 & 1.124 & 1 & 0.289 & 1.303 \\
\hline Constant & 1.509 & 0.413 & 13.339 & 1 & 0.000 & 4.522 \\
\hline-2 Log likelihoods & & & & & & 462.724 \\
\hline $\begin{array}{l}\text { Cox and Snell R } \\
\text { Nagelkerke R Square }\end{array}$ & & & & & & $\begin{array}{r}0.070 \\
0.10\end{array}$ \\
\hline
\end{tabular}

\section{Market Validation}

Fermented drinks have unique preferences which produce from indigenous fruits where some consumers were concern about originality of the products which is local source and has unique taste. Food tests were conducted involved three companies in the health product industry through face-toface interviews. Responses and opinions that have been given covering a wide range of characteristics including taste, colour, texture and viscosity. Industry samples suggested the taste of fermented drinks produced by MARDI is too 'sharp', especially for ceri Terengganu flavor and it is segmented for adults except for pregnant women and consumers with gastric problems. This is due to the higher acid content compared to existing products on the market. However, the taste of MARDI's fermented drinks tea is tastier and can meet the tastes of consumers. For packaging, fermented drinks should be marketed in amber bottles to prevent it from being exposed to light and causing evaporation to occur which in turn causes an explosion. 
Fermented drinks has a specific market segment which is more targeted at the health -conscious as well as adult consumers. Effective and efficient marketing channels need to be selected to ensure that the product can reach the target users. The concept of Marketing Mix is should be implemented by taking into account the elements of the product, price, location and promotion. However, in the early stages in providing exposure and awareness on the advantages of this product, online promotion (Instagram, Facebook, website, television, radio) and direct promotion (pharmacy, premium outlet) should be done to ensure accurate information reaches consumers.

Raw materials are major issue that is often raised as it were indigenous fruits and difficult to access in Malaysia. This an important element to ensure the supply are always sufficient for continuous production to meet consumer's needs. Contract farming is the option to access the supply in Malaysia. Indonesia is one of the countries that had supply kuini as raw material which it taking into account the additional cost of imported products. The government intervention in promoting cultivation is very much needed, especially in highlighting new crop varieties such as indigenous fruits.

\section{Conclusion}

This study identifies the acceptance of consumers and industry players towards the products developed by MARDI based on selected indigenous fruits. Food testing conducted on fermented drinks produce by MARDI and equivalent product in the market showed consumers are fond of the characteristics of MARDI product in terms of fruit taste, aroma, viscosity and fibre. The responds on willingness to pay found that consumer would pay with lower than the price that has been set. As consumer awareness of health increases, it was an opportunity for the health food industry to further expand the functional food market. However, raw materials are a major issue in the production of the product.

Government support is needed to encourage the indigenous fruits cultivation in Malaysia. It can be done through the provision of seed subsidies and financial resources to farmers in expanding and increasing the supply of these raw materials for the production of value-added products. Agencies / private companies' involvement as industrial driven is needed in creating intensive / commercial plantations in initiatives to commercialize downstream products based on indigenous fruits. Collaboration between research institutions and companies is good to catalyse the development of this industry through consumer awareness campaigns and the create market segment. Feedback on commercial prospects provided by the company / industry is important to ensure that the product meet consumer needs in industry perspective and the method can reduce the cost for product to penetrate the market. The situation is supported by the risk measurement approach which are technology push and demand pull. A technology produced according to market demand is lower risk as the existing market will ensure that the product meet consumers demand and give benefit to society.

The study is important in help future researchers in determining functional food production. The selection of raw materials that contain high nutrients is able to attract consumers to use health food products. The intervention of the authorities is important in educating consumers in Malaysia about the benefits of functional food intake.

\section{References}

Andreessen, M. (2021). A Step-by-Step Guide to Product-Market Validation. Retrieved from https://www.singlemindconsulting.com/blog/a-step-by-step-guide-to-product-market-validation/ on March 2021.

Corbo, M.R., Bevilacqua, A., Petruzzi, L., Casanova, F.P. \& Sinigaglia, M. (2014). Functional beverages: The emerging side of functional foods. Comprehensive Reviews in Food Science and Food Safety, 13(6), 1192 - 1206.

Dan Olsen. (2015). The Lean Product Playbook: How to Innovate with Minimum Viable Products and Rapid Customer Feedback. John Wiley \& Sons Inc 
Dimidi, E., Cox S.R., Rossi, M. \& Whelan, K. (2019). Fermented foods: Definitions and characteristics, impact on the gut microbiota and effects on gastrointestinal health and disease. Nutrients, 11(8), 1806.

Hanemann, M. (1984). Welfare evaluation in contingent valuation experiment with discrete responses. American Journal of Agricultural Economics, 66, 332-341

Hanley N. \& Barbier E.B. (2009) Pricing Nature: Cost - Benefit Analysis and Environmental Policy. heltenham: Edward Elgar, USA

Hanley, N. \& Barbier, E.B. (2009). Cost-Benefit Analysis and Environmental policy. Edward Elgar, USA

Hoehn J, Randall A. (1987). A satisfactory benefit cost indicator from contingent valuation. Journal of Environmental Economics and Management, 14, 226-47.

Kok, C.R. \& Hutkins, R. (2018). Yogurt and other fermented foods ad sources of health-promoting bacteria. Nutrition Reviews, 76(1), $4-15$.

Kombucha Market (By Flavors: Original, Flavoured; By Distribution Channel: Supermarkets, Online Stores, Health Stores) - Global Industry Analysis, Market Size, Opportunities and Forecast, 2018 - 2026. Retrieved from https://www.acumenresearchandconsulting.com/kombucha-market on March 2021

Krystallis, A. \& G. Chryssohoidis. (2005). Consumers' willingness to pay for organic food: Factors that affect it and variation per organic product type. British Food Journal, 107(5), 320- 343

Liburdi, K., Bernini, R. \& Esti, M. (2020). Fermented beverages: Geographical distribution and bioactive compounds with health benefits. In: New and future developments in microbial biotechnology and bioengineering - Microbial biomolecules: Properties, relevance and their translational applications. Edited by: Rodrigues, A.G. Elsevier, Netherlands. $131-151$.

MacCallum, R. C., Widaman, K.F., Zhang, S., \& Hong, S. (1999). Sample size in factor analysis. Psychological Methods, 4, 84-99.

Mvududu, N. H., \& Sink, C. (2013). Factor analysis in counseling research and practice. Counselling Outcome Research and Evaluation, 4(2), 75-98

Richard, A., Johnson \& Dean W. W. (2007). Applied Multivariate Statistical Analysis (6th Edition). USA: Pearson Education Publications

Sahu, L. \& Panda, S.K. (2018). Innovative technologies and implications in fermented food and beverage industries: An overview. In: Food Microbiology and Food Safety. Edited by: Panda, S.K. and Shetty, P.H. Springer Nature, $1-23$.

Saxe L. (2021). Fermented Foods Are Up 149 Up 149\% - As Long As They're Unfamiliar. Forbes. Retrieved from https://www.forbes.com/sites/lizzysaxe/2019/02/06/fermented-foods-are-up149-percent-as-long-as-theyre-unfamiliar/\#5f5043a9673f on January 2021

Semick, J. (2021). Lean Market Validation: 10 Ways to Rapidly Test Your Startup Idea. Retrieved from https://www.productplan.com/blog/lean-market-validation-10-ways-rapidly-test-startupidea/ on March 2021

Stanton, Emms, \& Sia. (2011). Malaysia's Market for Functional Foods, Nutraceuticals and Organic Foods. An Introduction for Canadian Producers and Exporters. Counsellor and Regional AgriFood Trade Commissioner, South East Asia

Watawana, M.I., Jayawardena, N., Gunawardhana, C.B. \& Waisundara, V.Y. (2015). Health, wellness, and safety aspects of the consumption of kombucha. Journal of Chemistry, 591869: 1 - 11.

Williamson, A. R., Hunt, A. E., Pope, J. F., \& Tolman, N. M. (2000). Recommendations of dietitians for overcoming barriers to dietary adherence in individuals with diabetes. The Diabetes Educator, 26, 272-278 